\title{
BIM in Multifamily Design \& Construction
}

\author{
Matt Jefferies ${ }^{1}$, Swarnali Ghosh Dastider ${ }^{2}$ \\ ${ }^{1}$ Washington University in St. Louis, St. Louis, MO, USA \\ ${ }^{2}$ School of Engineering \& Applied Science, Washington University in St. Louis, St. Louis, MO, USA \\ Email: sghoshdastider@tuskegee.edu
}

How to cite this paper: Jefferies, M. and Dastider, S.G. (2018) BIM in Multifamily Design \& Construction. Journal of Building Construction and Planning Research, 6, 331-339.

https://doi.org/10.4236/jbcpr.2018.64022

Received: November 7, 2018

Accepted: December 26, 2018

Published: December 29, 2018

Copyright $\odot 2018$ by authors and Scientific Research Publishing Inc. This work is licensed under the Creative Commons Attribution International License (CC BY 4.0). http://creativecommons.org/licenses/by/4.0/

\begin{abstract}
In 2014, the National Association of Homebuilders conducted an initial survey about the use of Building Information Modeling (BIM) in residential construction. They found that BIM had not been widely adopted, but there was interest in future use. Four years later, the authors, Prof. Ghosh Dastider and Matt Jefferies at Washington University in St. Louis used a similar methodology to see what has changed. They found a significant increase in BIM's application in the multifamily residential industry. Based on data collected from the re-conducted survey, the authors concluded with the future predictions on how use of BIM will accelerate in residential construction market in next few years. Few significant findings indicate increased use of BIM among contractors along with design built firms, as well as during the construction phase and life cycle analysis.
\end{abstract}

\section{Keywords}

BIM, Multifamily Design \& Construction, High-Rise Residential Technology

\section{Introduction}

In the 1980's, the personal computer pushed designers to transition from hand drafting to Computer Aided Drafting (CAD). In 1987, Autodesk employee Phil Bernstein coined the term Building Information Modeling (BIM), and ArchiCAD was released as the first commercial BIM software [1]. In the 1990's, BIM software could calculate construction time, and by 2000 , it could calculate construction cost. Today, BIM software can assist in all facets of the building process.

Historically, BIM typically has been popular on large commercial building projects such as libraries, museums, office buildings, and hospitals. Multifamily housing, however, has always been one of the most cost-sensitive building types in the design \& construction industry. Because of the thin return on investment 
(ROI) margins, developers, constructors, and architects have hesitated to use BIM technology on residential projects because of the initial investment required for its success.

In 2014, The National Association of Homebuilders [2] conducted a survey of the use and appropriateness of Building Information Modeling (BIM) in residential construction. While it showed a lack of familiarity among contemporary stakeholders in the housing industry, it also suggested a willingness by most of those stakeholders to implement BIM technologies in the future. Written four years after the original survey, this paper presents the results of recent methodical research regarding the current use of BIM technology in multifamily residential projects, while investigating its appropriateness in this specialty market. In addition, it reviews current trends in BIM's application to increase efficiency in the residential design and construction industry.

\section{2014 Building Information Modeling (BIM) Survey}

The NAHB BIM survey is a bi-annual report written by the NAHB Economics and Housing Policy Group. The survey assessed participants' familiarity with BIM and use of BIM features among single and multifamily builders and designers, focusing on the number of firms using BIM and how they were using the technology for production, including two-dimensional drafting, trade coordination, integrated project delivery, thermo modeling, and shop drawing generation, etc. The results showed relatively little use of BIM (22\%) in multifamily residential projects. However, 47\% of responding firms indicated that they would be interested in adopting BIM in the future. The survey also showed that BIM was primarily used for drafting, and not for its extended features like integrated project delivery, thermo modeling, or code review. Therefore, the need to revisit and investigate the variance in usage of BIM in the residential design industry in 2018 seemed vital, thus serves as foundation for this research.

\section{Methodology}

The study was strategically divided into three phases to promote extensive data collection based on the authors' literature research. It started with an extensive literature study, followed by a survey of approximately 296 residential projects across the multifamily residential industry. Several of these projects were located in St Louis, Missouri, USA, whereas others were located throughout the different states within the USA to include diversity of markets. Finally, the third phase included collected data analysis and reporting.

Phase 1: Literature Study

The literature study addressed a variety of topics including BIM in the real estate development process and in Life Cycle analysis and cost, and BIM's impact on return on investment [3] [4]. Among the few scholarly articles about BIM's role in the multifamily residential market, the authors found discussions of current issues and challenges, as well as of theoretical and methodological predica- 
ments [5]. However, the authors found several ostensibly related topics that supported their research. The major topics included business value of BIM by Smart Market Report, developing a financial model for savings and ROI Calculation of construction projects [3], comparative analysis of BIM in the Multi-family House and Single-family [6], discursion about the value of BIM for real Estate developers and owners [5] etc. These articles helped formulate the survey questionnaire.

Phase 2: Survey

Based on the authors' initial conclusion from the literature study, a 20-question survey was formulated to gather information on the number of employees, type of employees, and type of firms using BIM in residential construction. Three articles namely, Virtual Design and Construction: Themes, Case Studies and Implementation Suggestions [7], Enhancing Pre-Construction Decision-Making on Sustainable Commercial Building Projects [8] and Getting Building Information Modeling to the Bottom Line [9] had greatly influenced the formation of the survey.

The survey was sent to 14 different design, design-build, construction and real estate companies involved in residential market. Some of these companies are local to St Louis, Missouri, USA and some have offices in multi-location within the United States. The investigation criteria included total BIM users, application stages, ease of application, stake holders' involvement, and financial aspects of BIM in the residential market, as well as, variety in application amongst stake holders. Information was gathered on 700 projects from multiple designers, builders, and developers. Of the total 700 projects, 296 were residential and had 3363 employees in total. The authors' investigation focused on changes in BIM's application since the release of the 2014 NAHB survey based on the data collected from these 296 projects. The results are presented in detail below.

\section{Post Survey Findings}

\section{Phase 3: Survey Results}

Based on the data collected from this survey done by the author in 2018, the results are tabulated focusing on different users' group, stakeholders participation and design \& construction phases as described below.

\section{$\underline{\text { BIM Users }}$}

The survey by the authors in 2018 showed that, 23\% (1006 of 3363) of employees were using BIM technology in their offices. This proves a significant increase in BIM application in the multifamily residential market compared to the previous survey done by NAHB in 2014 which indicated that majority (83\%) of the respondents related to the multifamily residential market were unfamiliar with BIM's adoption [2]. However, 2018 survey data also showed that, out of the $23 \%$ of BIM users, $32 \%$ (476) are using BIM on multi-family residential projects as demonstrated in Figure 1 and Figure 2.

Stakeholders Participation

Another important finding was how stakeholders in residential projects were in- 
volved with BIM. The 2014 NAHB report stated that "architects are the most likely group to be familiar with BIM (68\%), compared to $20 \%$ of multifamily builders" [2]. As shown in Figure 3, this new survey found an increased application of BIM among contractors (30\%) and design build (80\%) since 2014. On the other hand, design-build firms which employee both architects and contractors have maximum numbers of BIM users compared to the firms that has only designers or contractors signifying increased BIM collaboration among the stake holders.

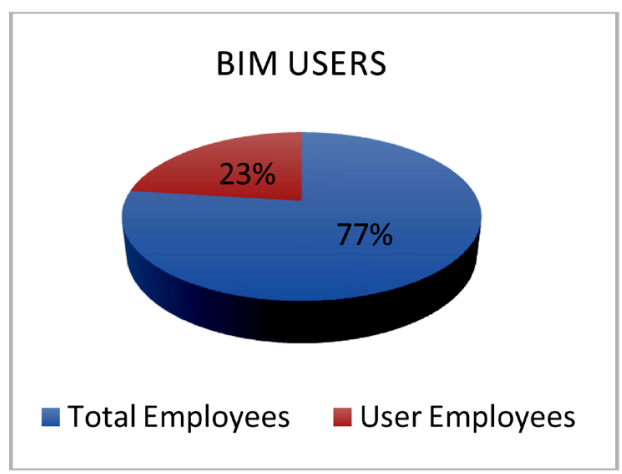

Figure 1. BIM users.

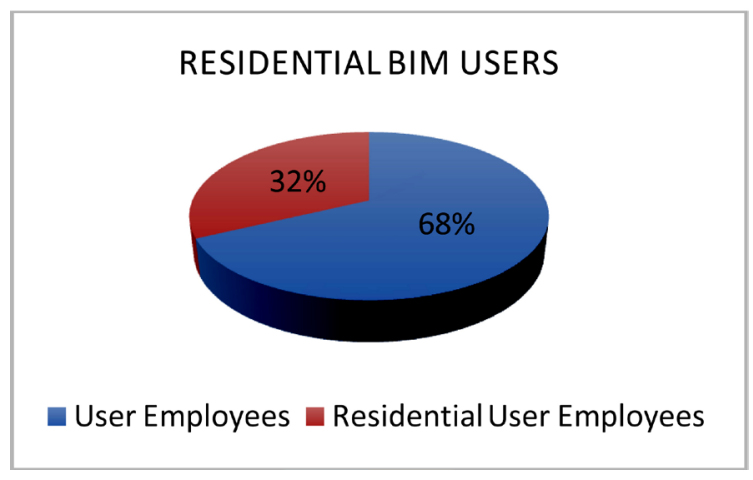

Figure 2. Residential BIM users.

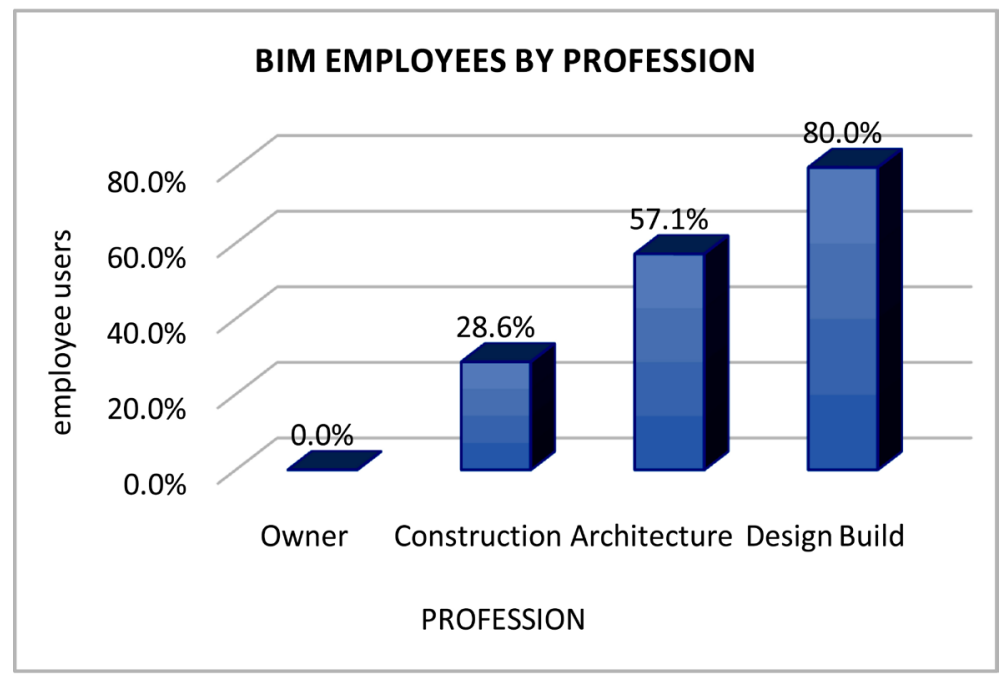

Figure 3. BIM employees by profession. 


\section{Owner/Developers}

Figure 4 indicates the variance in stakeholders' participation in using BIM based on the survey results done in February 2018. The owner/developer graph illustrates that developers are indirectly involved with BIM as shown in Figure 4. While they do not use BIM as a design tool in the office, they are able to use BIM models to monitor design intentions and coordination. This creates efficiency and allows for better quality control.

General Contractors

Data received from the survey done in 2018 indicates that $28.6 \%$ of employees working for general contractors company were using BIM as a means of production on residential projects. The survey indicates that small-scale contractors have yet to explore the full benefit of BIM due to lack of available expertise, however most are inclined to its future implementation. Conversely, large-scale contractors expressed using BIM since its inception and mentioned financing a department dedicated to Virtual Design and Construction (VDC), which is closely related to BIM. Though large general contractors interviewed stated that residential work only accounts for 20 of their 200 projects (10\%), BIM is still used as the production tool regardless of the project type.

Architects

Similar to the 2014 NAHB survey findings, architects still remain as the top user of BIM. Based on the current survey results it is evident that $57.1 \%$ of the employees at architectural firms are using BIM on residential projects. It is established that, architectural firms are using BIM for projects greater than 140 units. According to multiple users interviewed, BIM allowed for better organization of large residential projects. For example, unit studies were developed at an accelerated pace and could receive live feedback from other stake holders. In addition, firms indicated that BIM allowed for collaboration between multiple architects. All architecture firms interviewed expressed having dedicated BIM specialists in charge of maintaining their collaborative work-share system.

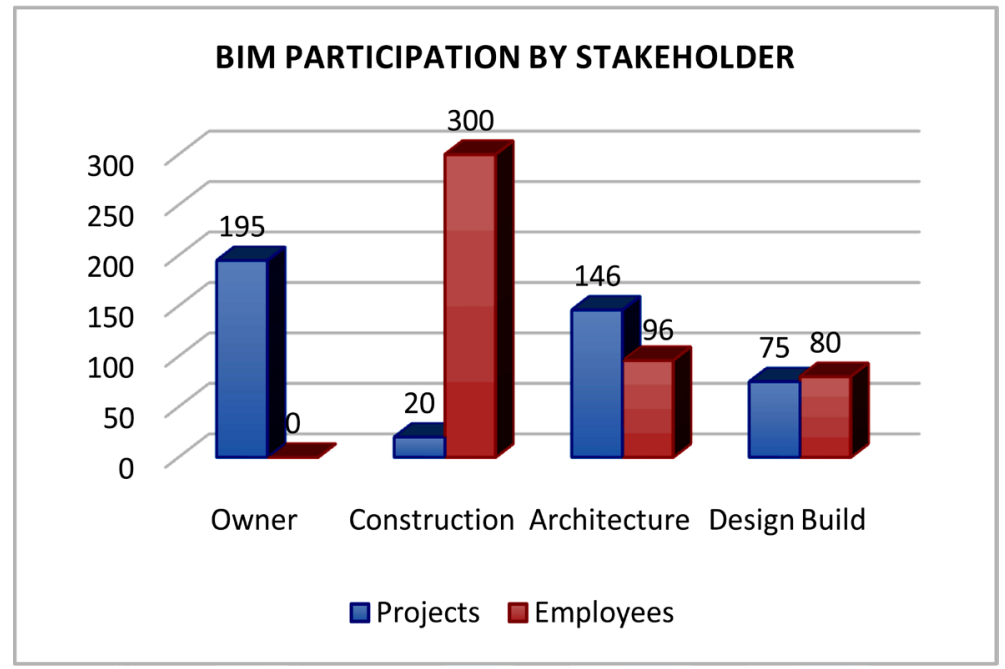

Figure 4. BIM participation by stakeholder. 


\section{Design-Build Firms}

It appears from the survey done in 2018 that, $80 \%$ of employees at design-build firms are involved in BIM. In a design-build office setting, communication is essential between design and construction personnel. Any mistakes in the design or construction will leave the firm liable. Therefore, a design-build firm benefits from competent BIM personnel. Design-Build personnel surveyed indicated using BIM on all phases of the building process without exception.

\section{Additional Results}

Another interesting finding of this research supports the growth of BIM in the residential industry is its use during various phases of design. Historically, BIM tools were used for producing construction documents and "reviewing three dimensional plans" [2]. This survey done in 2018 indicates that firms are implementing BIM in various phases besides construction, including concept, schematic design, design development and operation and maintenance phases. Refer to Figure 5.

\section{Concept \& Schematic Design}

Survey done in 2018 yielded similar results in Concept and schematic design phase as design phase, mainly because same personals being involved in both applications. As indicated in the Figure 5, it appears that $98 \%$ of 476 users are implementing BIM during concept and schematic design phase. According to the survey, BIM application during the schematic design and concept phases established improved collaboration among design team members at the beginning of the project, which renders efficiency and reduces errors.

Lifecycle Analysis \& Maintenance

On the other hand, $64 \%$ of 476 employees working for construction firms are

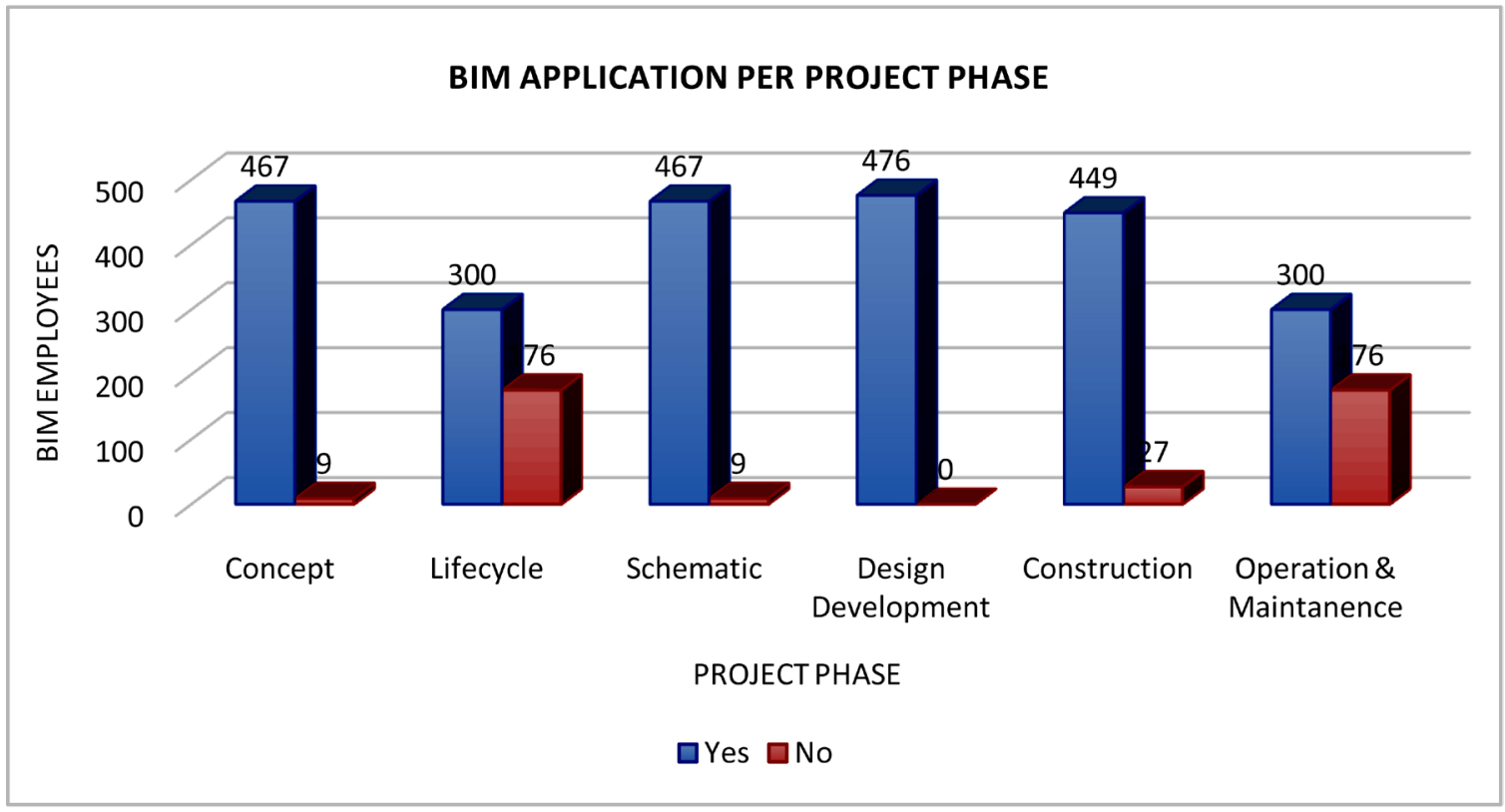

Figure 5. BIM application per project phase. 
using BIM for lifecycle analysis (LCA), during the construction phase as well as the operation and maintenance phase. Employees, represented in the Figure 5, participating in lifecycle analysis used other technology to monitor operational costs throughout the buildings life. The survey results showed a direct correlation between BIM's adaptation for lifecycle analysis and maintenance. Firms using BIM to create lifecycle analysis data are also inclined to use BIM for monitoring building systems.

Design Development

However, the survey done in 2018 reported BIM as a proven tool during design development phase, as all that took the survey are using it during this phase as demonstrated in the Figure 5. Most project stakeholders believe design development is the best time to begin collaborative work thru' BIM. During this phase, building elements grow in complexity and reach the level of development that often requires collaborative work between designers, engineers, and contractors; therefore, BIM offers the popular platform.

\section{Construction}

BIM's effectiveness during construction phase is a close follower to the design development phase. The survey indicates that $94 \%$ of 476 employees are using BIM during the construction phase as shown in the Figure 5. Users reported that BIM software led to an efficient building and decision-making process with minimal change orders. Firms also stated that clash detection was an important benefit of BIM software in residential projects as this approach prevented many costly mistakes on the drawing board rather on field.

\section{Conclusions}

Based on this study it can be concluded that, use of Building Information Modeling (BIM) is evolving in multifamily residential work. Firms are increasingly finding new ways to improve the process of using BIM. There has been an increased use of BIM among stakeholders along with construction and architecture firms. Development firms have benefited from the creation of BIM models while design-build firms have used BIM models to increase communication between construction and design personnel. In addition, this study indicates that BIM's use has evolved beyond the design development and construction phases. Multifamily stakeholders are using BIM as early as the concept design phase and as late as the building operations phase indicating BIM's increased application in all the life cycle phases of a construction project, starting from concept to facility maintenance.

Additionally, the findings of this research strongly indicate that BIM technology will be increasingly applied in multifamily projects and in increasingly diverse ways. Collaboration will extend beyond design as stakeholders and will come to include real estate agents, sales teams, and other business personnel. In addition, collaboration will occur during the entire duration of the project, as opposed to being limited to design development and construction. BIM will allow 
residential projects to be produced with increased efficiency, which for owners, will increase feasibility.

\section{Acknowledgements}

This research was supported by Henry Edwin Sever Institute at the Washington University in St Louis. We thank our colleagues Prof. Steve Bannes from the Sever Institute and Prof. James Ballard from the Engineering Communication Center at the Washington University in St Louis who provided insight and expertise that greatly assisted this research.

We also thank our survey participants Affordable and Market Rate housing developer, PYATOK Architects, Steinberg Architects, KAI Design Build, E.M Harris, Hybrid Architects, Christner Architects, McCormick Baron Salazar, Clayco, Alberici, The Carmel Partners, Turner Construction Company, HOK and UIC for participating in the survey and sharing their wisdom and experience with us.

\section{Conflicts of Interest}

The authors declare no conflicts of interest regarding the publication of this paper.

\section{References}

[1] Quirk, V. (2012) A Brief History of BIM. ArchDaily. https://www.archdaily.com/302490/a-brief-history-of-bim

[2] National Association of Home Builders (2014) 2014 Building Information Modeling (BIM) Survey.

[3] Salih, S. (2012) The Impact of BIM/VDC on ROI: Developing a Financial Model for Savings and ROI Calculation of Construction Projects. Department of Real Estate and Construction Management, vol. Master of, no. 177.

[4] Love, P.E.D. and Li, H. (2000) Quantifying the Causes and Costs of Rework in Construction. Construction Management and Economics, 18, 479-490. https://doi.org/10.1080/01446190050024897

[5] Clason, J.C. (2008) Building Information Modeling: Value for Real Estate Developers and Owners. http://hdl.handle.net/1721.1/42036

[6] Santos, R. and Aguiar Costa, A. (2016) BIM in LCA/LCEA Analysis: Comparative Analysis of Multi-Family House and Single-Family. CERIS, Instituto Superior Técnico, Universidade de Lisboa, Av. Rovisco Pais 1, 1049-001, Lisboa, Portugal. http://www.irbnet.de/daten/iconda/CIB_DC29646.pdf

[7] Kunz, J. and Fischer, M. (2012) Virtual Design and Construction: Themes, Case Studies and Implementation Suggestions. CIFE Working Paper, vol. 97, 50. https://purl.stanford.edu/gg301vb3551

[8] Abraham, K., et al. (2014) Enhancing Pre-Construction Decision-Making on Sustainable Commercial Building Projects. CIFE Technical Report, 15.

[9] Young, N.W., Jones, S.A., Bernstein, H.M., Gudgel, J.E., et al. (2009) The Business Value of BIM: Getting Building Information Modeling to the Bottom Line. Construction, 213-222. 


\section{Appendix A}

\section{Literature Study}

AIA, and AIA California Council (January, 2010) Integrated Project Delivery: Case Studies. McGraw Hill Construction, 1-62.

AIACC (November, 2008) Integrated Project Delivery Frequently Asked Questions. 4.

Elvin, G. (2010) Principles of Integrated Practice in Architecture, Journal of Architectural and Planning Research, 27, 287-300.

Hanna, A.S. (2016) Benchmark Performance Metrics for Integrated Project Delivery. Journal of Construction Engineering and Management, 142, 1-9. https://doi.org/10.1061/(ASCE)CO.1943-7862.0001151

Ling, F.Y.Y., et al. (2013) Key Relational Contracting Practices Affecting Performance of Public Construction Projects in China. Journal of Construction Engineering and Management, 1-12.

Pollock, A. (2011) BIM in Academia. Ecobuilding America, 1-8. http://www.som.com/FILE/20367/bim-in-academia.pdf

Sahil, A. (2016) Adoption of Building Information Modeling in Developing Countries. Degree of Master Thesis, Colorado State University, Fort Collins.

Senescu, R., Haymaker, J. and Fischer, M. (July, 2011) Design Process Communication Methodology: Improving the Efficiency and Effectiveness of Collaboration, Sharing, and Understanding. CIFE Technical Report \# TR197, Stanford University, Stanford, CA. https://purl.stanford.edu/xy729bm8702

Thomsen, C. (2007) Managing Integrated Project Delivery-Concepts and Contract Strategies. CMAA, 35, 1-52. https://doi.org/10.1093/carcin/bgu172

Yori, R. (2011) The Cost of Not Doing BIM: Education and Professional Development. Journal of Building Information Modeling, 28-29.

https://www.som.com/ideas/research/the_cost_of_not_doing_bim 